\title{
The level of awareness and production of English lexical stress among English language teacher trainees in Malaysia
}

\author{
Ernie Adnan ${ }^{1,2}$, Stefanie Pillai ${ }^{2 *}$, and Poh Shin Chiew ${ }^{2}$ \\ ${ }^{1}$ Scholarship and Financing Division, Ministry of Education, Aras 2, No. 2, Menara 2, Jalan P5/6, \\ Presint 5, Putrajaya, Malaysia \\ ${ }^{2}$ Faculty of Languages \& Linguistics, University of Malaya, 50603 Kuala Lumpur, Malaysia
}

\begin{tabular}{|c|c|}
\hline $\begin{array}{l}\text { ABSTRACT } \\
\text { The realisation of lexical stress among Malaysian speak } \\
\text { from other varieties of English. In spite of this, there is } \\
\text { model in the teaching of English in Malaysia. In relati } \\
\text { lexical stress among a group of Teaching of English as a } \\
\text { objectives of this paper are to assess the overall level of a } \\
\text { to examine their production of lexical stress, and to det } \\
\text { awareness and production. The method used to elicit da } \\
\text { Stress Awareness Test (LSAT), completed by } 104 t \\
\text { objective were obtained by recording the trainees readin } \\
\text { findings from the LSAT indicate that most of the tr } \\
\text { awareness of English lexical stress. They were generall } \\
\text { of a stressed syllable. In addition, the findings from th } \\
\text { suggest that they did not have a systematic pattern of str } \\
\text { of stress being vowel lengthening. In contrast, most } \\
\text { characteristic of a stressed syllable. Hence, there is an }\end{array}$ & $\begin{array}{l}\text { s. The } \\
\text { them, } \\
\text { vel of } \\
\text { exical } \\
\text { econd } \\
\text { s. The } \\
\text { vel of } \\
\text { ristics } \\
\text { rdings } \\
\text { relate } \\
\text { s the } \\
\text { reness } \\
\text { igs in } \\
\text { stress } \\
\text { ven in } \\
\text { stress }\end{array}$ \\
\hline \multicolumn{2}{|c|}{ Keywords: Acoustic correlates of stress; English pronunciation; lexical stress; teacher trainees } \\
\hline 1 & \\
\hline Gin & \\
\hline \multicolumn{2}{|c|}{$\begin{array}{l}\text { How to cite (in APA style): } \\
\text { Adnan, E., Pillai, S., \& Poh, S. C. (2019). The level of awareness and production of English } \\
\text { lexical stress among English language teacher trainees in Malaysia. Indonesian Journal of } \\
\text { Applied Linguistics, 9, 98-107. doi: 10.17509/ijal.v9i1.15767 }\end{array}$} \\
\hline
\end{tabular}

\section{INTRODUCTION}

While several studies claim that lexical stress is important for speech to be intelligible (Field, 2005), others feel that it may not be necessary (Jeong, Thorén, \& Othman, 2017). However, as future teachers of English, the assumption is that if teachers are aware of how English stress works in the pedagogic model, they can then use this knowledge to compare it with their own realisations of stress. Tupas (2010), for instance, points out that it is crucial for teachers to be aware of language features in different varieties of English. This is because such awareness will enable teachers to be more critical in reasoning the pedagogical models applied in their English classroom.

In order to create awareness of the Malaysian variety of English, there must be a body of knowledge that teachers can access and compare with the prescribed pedagogic model, which in the Malaysian

\footnotetext{
* Corresponding Author

Email: stefanie@um.edu.my
} 
context, is British English (Kementerian Pendidikan Malaysia, 2015, 2016). However, local features of English pronunciation are not focused upon in teacher training. This may be due to the perception that equates intelligibility with having a native-like accent such as Received Pronunciation (RP). In addition, not only does research on Malaysian English pronunciation tend to focus on colloquial and learner varieties of English, there is also a lack of research on the prosodic features of Malaysian English, especially on lexical stress (Tan, 2016). In particular, there is a dearth of published research on the awareness and perception of lexical stress in relation to Malaysian English. Thus, it is perhaps not surprising that features of Malaysian English pronunciation are largely ignored in English language teacher training programmes. In an attempt to contribute to the body of knowledge on the prosodic features of the Malaysian variety of English, this paper focuses on the awareness and production of lexical stress among English language teacher trainees. The first question we address is what the level of awareness of English lexical stress is among the teacher trainees. The second question we examine is how they realise lexical stress, and the third one is the link between their level of awareness and their own production of lexical stress.

\section{Lexical stress in English}

In RP, lexical stress is typically fixed, but this is not a characteristic feature of all varieties of English and differences in lexical stress placement can be found even between native varieties of English, such as British English (BrE) and American English (AmE). An example of this is the word 'rotate': (BrE roTATE and AmE ROtate). Stress placement in other varieties of English may also differ (Low, 2015) as there may be a shift in the placement of the stressed syllable (e.g., SUMmarise to summaRISE and inforMAtion to INformation).

Roach (2009) describes general rules for determining the stressed syllables in BrE. However, he argues that these rules may not be conclusive for all the words in English. He points out that for a two-syllable noun, the first syllable tends to be stressed, whereas, for verbs, adjectives, and adverbs, the second syllable is stressed. In three-syllable nouns and adjectives, the first syllable is stressed, but for verbs and adverbs, the second syllable is stressed. Examples of these are as following:

Two-syllable nouns (e.g., PAper)

Two-syllable verbs (e.g., aTTEND) adjectives (e.g., aLIVE) and adverbs (e.g., perHAPS)

Three-syllable nouns (e.g., FAmily) and adjectives (e.g., DANgerous)

Three-syllable verbs (e.g., reMEMber) and adverb (e.g., forEver)

However, there are always exceptions. If syllables contain a schwa, they are not stressed. For example, in the three-syllable adverb 'probably', the first syllable (e.g., PRObably) is stressed instead of the second because of the weak form of the vowel in the second syllable. Similarly, in the two-syllable verb 'open', the stressed syllable falls on the first syllable (e.g., Open) rather than the second. Such exceptions might become the source of difficulties for language learners when learning how to stress words in English.

A stressed syllable is generally perceived to be more prominent than unstressed ones in the same word. This perception of prominence arises from a combination of features such as the stressed syllable usually being perceived as being higher, longer and louder than the other syllables in the word (Fry, 1958; Lehiste, 1970). Acoustically, these features can be measured in relation to fundamental frequency (F0), duration and intensity

\section{Lexical stress in the Malaysian variety of English}

Most studies on pronunciation in the Malaysian variety of English have focused on its segmental features (vowels and consonants) rather than suprasegmental features such as stress, rhythm and intonation. Findings from studies on stress have proposed that lexical stress in this variety is different from BrE (Baskaran, 2004; Hashim \& Tan, 2012; Platt, 1980; Rajadurai, 2006; Tan, 2016). The most notable finding is on the shift in the placement of stress in MalE whereby a stressed syllable is often shifted to a later syllable (Platt, 1980; Rajadurai, 2006). The shift to the final syllable is often accompanied by vowel lengthening (Platt, 1980). This final placement of stress can be observed when the same word is produced in different positions in a sentence as in the following example (Mat Nayan \& Setter, 2016): //white MOUNtain, you have to pass the white mounTAIN//

Similar results were reported by Hashim and Tan (2012, p. 62) where the shift takes place from an antepenultimate syllable to a penultimate syllable (e.g., CAmera to caMEra) and from a penultimate syllable to an antepenultimate syllable (e.g., spaGHEtti to SPAghetti). Stress in Malaysian English is also said to be positioned differently in disyllabic and polysyllabic words (Baskaran, 2004).

Another distinct characteristic of stress between the Malaysian and British variety of English is the number of stressed syllables in a word. Baskaran (2004) suggested that there might be a reduction or an increasing number of stressed syllables in a word like 'manufacturer'. Thus, an equal prominence may be given to both primary and secondary stress (e.g., MAnuFACture). Malaysian speakers also tend not to differentiate stress on pairs or words derived from the same root (Baskaran, 2004). This makes such words homophonous (e.g., imPORT for both the noun and verb).

\section{METHOD}

\section{Participants}

The participants comprised 104 trainees who were selected from five Teacher Education Institute (ITE) 
campuses located in the northern part of Malaysia. Permission was obtained from the Educational Planning and Research Division, Ministry of Education Malaysia to conduct the study and written consent was obtained from all the participants. The demographic information of the trainees was obtained from the first part of the Lexical Stress Awareness Test (refer to the following section). There was an equal proportion of Malay and
Malaysian Chinese trainees $(34 \%, \mathrm{n}=35)$, while 22 were Malaysian Indians (21\%). The rest of them were mainly from Sabah and Sarawak judging from their ethnic backgrounds $(11 \%, \mathrm{n}=12)$. Their diverse educational backgrounds were reflected in the language they most frequently used at home and elsewhere (see Table 1), with the majority of them speaking Malay and Mandarin.

Table 1. Languages most frequently used at home and outside the home

\begin{tabular}{lrrrrrrrrrrrrr}
\hline & \multicolumn{8}{c}{ Institute of Teacher Education (ITE) Campuses } \\
& ITE & \multicolumn{1}{c}{ ITE } & \multicolumn{1}{c}{ ITE C } & \multicolumn{1}{c}{ ITE D } & ITE E & Total \\
Languages & $\mathbf{1}$ & $\mathbf{2}$ & $\mathbf{1}$ & $\mathbf{2}$ & $\mathbf{1}$ & $\mathbf{2}$ & $\mathbf{1}$ & $\mathbf{2}$ & $\mathbf{1}$ & $\mathbf{2}$ & $\mathbf{1}$ & $\mathbf{2}$ \\
\hline Standard Malay & 10 & 12 & 2 & 3 & 2 & 6 & 1 & 9 & 1 & 5 & 16 & 35 \\
Malay (East Coast Variety) & 1 & - & - & - & 4 & 1 & 4 & 1 & - & - & 9 & 2 \\
Malay (Northern Variety) & 1 & - & 1 & - & 1 & - & 3 & - & 1 & 2 & 7 & 2 \\
Malay (Central Variety) & 2 & - & 1 & - & - & - & 2 & - & 5 & - & & 10 \\
Sabah Malay & 5 & 1 & 1 & 1 & 1 & 1 & 5 & 3 & - & - & 12 & 6 \\
Sarawak Malay & - & - & 1 & - & 2 & - & 3 & 1 & - & - & 1 & 6 \\
Mandarin & - & - & 18 & 19 & 5 & 6 & 8 & 7 & - & - & 32 & 31 \\
Tamil & 9 & 8 & - & - & - & - & 2 & 3 & - & - & 11 & 11 \\
English & - & 7 & 1 & 2 & - & 1 & - & 4 & - & - & 14 & 1 \\
Telegu & 1 & 1 & - & - & - & - & - & - & - & - & 14 & 1 \\
TOTAL & 29 & 29 & 25 & 25 & 15 & 15 & 28 & 28 & 7 & 7 & 104 & 104 \\
\hline
\end{tabular}

1: Language used at home 2: Language used outside the home

\section{Lexical Stress Awareness Test}

The Lexical Stress Awareness Test (LSAT) consisted of two sections. In the first section, demographic information was elicited from the participants, while the second section focused on the participants' level of awareness of lexical stress in English. The questions, the scoring method and the rubrics for the levels of awareness were validated by three experts who had an average of 14 years of teaching experience on the Teaching of English as a Second Language (TESL) undergraduate programme at ITEs.

The first question in the second section of the test required the participants to describe the characteristics of a stressed syllable in a word. This was followed by a task where the participants had to mark the stressed syllables in five disyllabic and five trisyllabic words, 10 words with prefixes and suffixes, and three compound words. These words were selected from various parts of speech to ascertain whether the participants were able to identify stress in different categories of words. The last question in the test examined the participants' awareness of the differences between primary and secondary stress in a word.

Subsequently, $10 \%$ of the tests were moderated by two of the experts. The moderated scripts were then compared to the scripts marked by the first author for consistency. The final scores were then matched to the rubrics prepared earlier. Table 2 provides an explanation of the rubrics for the three levels used to place the participants.

Table 2. Rubrics for levels of English lexical stress awareness

\begin{tabular}{lll}
\hline $\begin{array}{l}\text { Levels of } \\
\text { awareness }\end{array}$ & $\begin{array}{l}\text { Range of } \\
\text { marks }\end{array}$ & Descriptors \\
\hline High & $17-24$ & $\begin{array}{l}\text { Demonstrates a high level of awareness in most areas of English lexical stress. Able to } \\
\text { recognize almost all the key concepts and shows a high level of sensitivity towards the } \\
\text { general rules of lexical stress in English }\end{array}$ \\
Intermediate & $8-16$ & $\begin{array}{l}\text { Demonstrates a satisfactory level of awareness in some areas of English lexical stress. } \\
\text { Able to recognize some key concepts and show a satisfactory level of sensitivity towards } \\
\text { the general rules of lexical stress in English. }\end{array}$ \\
Low & $0-7$ & $\begin{array}{l}\text { Demonstrates a low level of awareness in most areas of English lexical stress. Able to } \\
\text { recognize only a limited range of the key concepts and shows a low level of sensitivity } \\
\text { towards the general rules of lexical stress in English. }\end{array}$ \\
\hline
\end{tabular}

\section{Lexical stress production task}

In order to examine how the participants realised lexical stress in English, a production task was designed. One of the components of the production task was the elicitation of a total of four high frequency disyllabic nouns selected from the British National Corpus (BNC), 2001 (Leech, Rayson, \& Wilson, 2001). The words were put in carrier sentences to provide context to the word, and to make the task more natural than reading a list of words (see Appendix A for the test words used). 
The words were read aloud by 35 of the Malay participants.

\section{Acoustic correlates of stress}

The audio files of the test words were annotated and analysed using Praat version 6.0.28 (Boersma \& Weenink, 2017). Figure 1 shows how a test word was segmented and measured. For the duration, the vowels were segmented based on the visual cues in the spectrogram and perceptual examination. The duration of each vowel was then measured from the onset to the offset of the vowel. To ascertain pitch change, the onset and offset of the fundamental frequency (F) on the voiced portion of the test vowels was measured. For amplitude, the average amplitude for each vowel was measured. Statistical analysis was conducted on the results of the production task by using independent t-test (with an alpha level of .05).

\section{FINDINGS}

Lexical Stress Awareness Test (LSAT)

Table 3 shows the distribution of marks for each level at five ITEs. Based on the LSAT, more than half of the participants $(n=64,62 \%)$ were placed at the Intermediate level, with the average marks being 14 (SD $=4.4$ marks). The range of marks for all five campuses was 3 to 22 out of 24 marks.

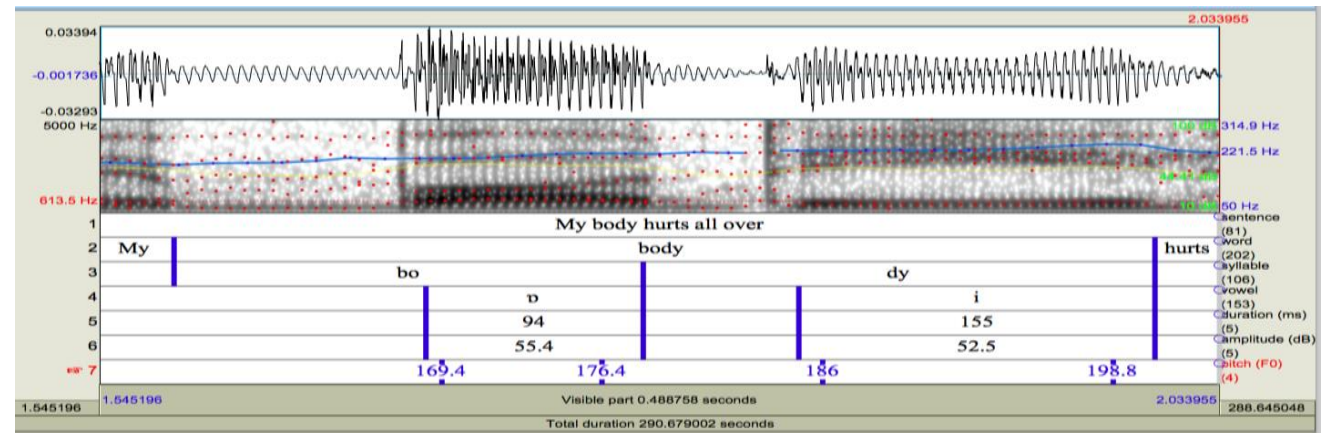

Figure 1. Annotations of the word 'body'

Table 3. Level of awareness about lexical stress among teacher trainees at five campuses of the Institute of Teacher Education (ITE)

\begin{tabular}{ccccc}
\hline $\begin{array}{c}\text { Institute of Teacher Education } \\
\text { Campuses }\end{array}$ & $\begin{array}{c}\text { High } \\
(\mathbf{1 7 - 2 4})\end{array}$ & $\begin{array}{c}\text { Awareness Levels } \\
\text { Intermediate } \\
(\mathbf{8 - 1 6})\end{array}$ & $\begin{array}{c}\text { Low } \\
(\mathbf{0 - 7})\end{array}$ & $\begin{array}{c}\text { Total no of } \\
\text { participants }\end{array}$ \\
\hline ITE A & 1 & 23 & 5 & 29 \\
ITE B & 11 & 14 & 0 & 25 \\
ITE C & 6 & 8 & 1 & 15 \\
ITE D & 12 & 15 & 1 & 28 \\
ITE E & 2 & 4 & 1 & 7 \\
Total & 32 & 64 & 8 & 104 \\
\hline
\end{tabular}

Almost half of the participants were not able to answer the first $(49 \%, \mathrm{n}=51)$ and the third question $(41 \%, n=43)$ in the test, with scores of 0 for both questions. For the $53(51 \%)$ participants who were able to provide at least one of the characteristics of stress, a higher pitch was the most frequently provided characteristic followed by a longer duration as shown in Table 4. As for stating the difference between primary and secondary stress, 61 (59\%) of the participants provided appropriate answers, while almost half of the ones who obtained a zero mark did not provide any answers.

Table 4. Characteristics of lexical stress

\begin{tabular}{lcr} 
Characteristics & Number & \% \\
\hline Higher pitch on stressed syllable & 38 & 12 \\
Longer duration of syllable & 35 & 11 \\
Louder syllable & 28 & 9 \\
\hline
\end{tabular}

Although almost half of the participants were not able to describe the characteristics of stress, the majority of the them $(n=72,69 \%)$ were able to mark the stressed syllable in words in citation form. The majority of the participants did not have difficulties identifying stress in disyllabic and trisyllabic words with 92\% $(n=96)$ of them managing to identify stress in at least four out of eight of the words for question 2a. Figure 2 shows responses for identifying stress in disyllabic and trisyllabic words among the 104 participants. For the word 'celebrate', many of the participants $(n=67,64 \%)$ did not select the first syllable as being the stressed one. In addition, almost half of the participants did not identify the stressed syllable in the word 'compact'. This is perhaps not surprising as there is a tendency to produce the full vowel in the first syllable of this word in the Malaysian variety of English (Pillai \& Ong, 2018), and thus this syllable is more likely to be stressed or perceived to be stressed. 


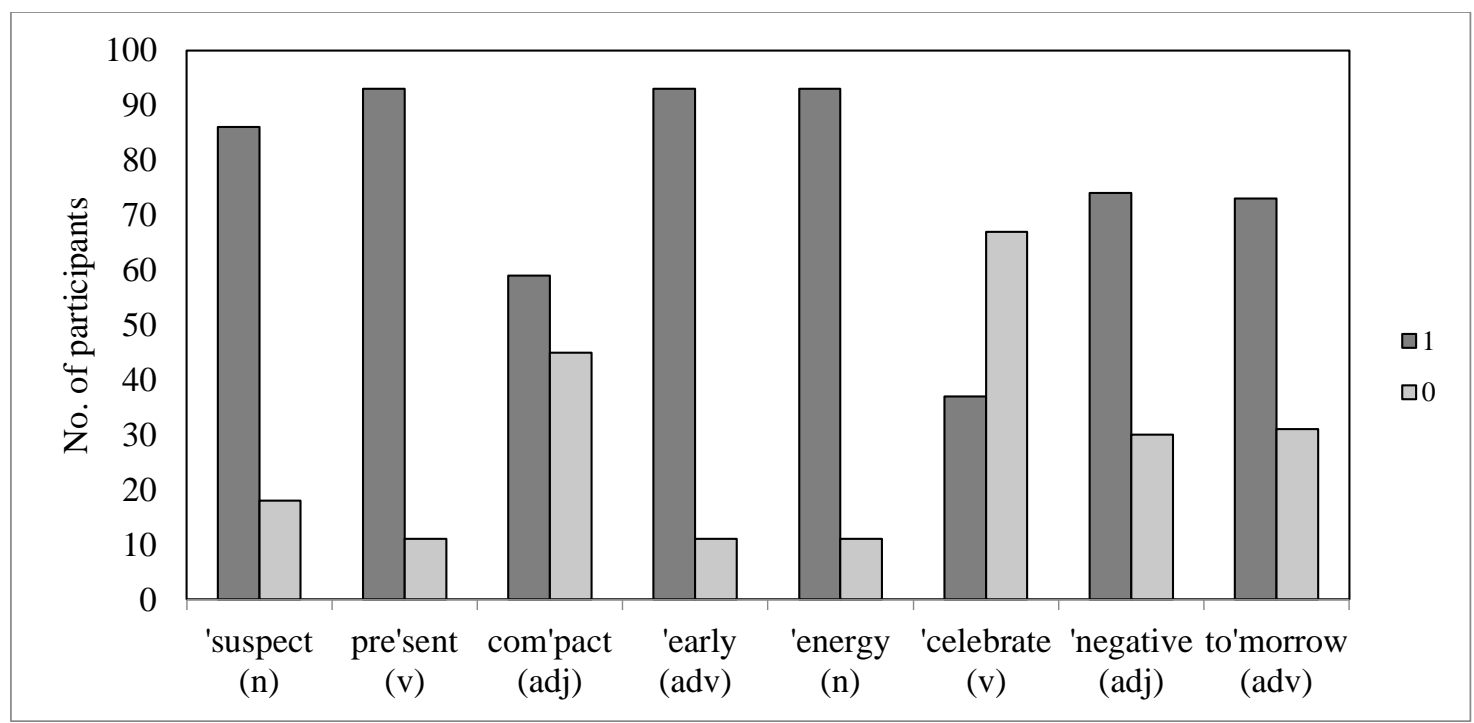

1: Identified stressed syllable

0: Did not identify stressed syllable

Figure 2. Identification of stressed syllables in disyllabic and trisyllabic words

In the words with prefixes and suffixes in question $2 \mathrm{~b}$ of the LSAT, the percentage of those who were able to identify the stressed syllable decreased with only $63 \%(n=65)$ of the participants identifying stress in at least four out of eight of the words (see Figure 3). More than $70 \%$ of the participants did not identify the stressed syllable in the words 'incomplete' (77\%) and 'historical' (72\%), while only about half of them identified the stressed syllable in 'democracy'.

For the compound words in question 2c, 71 (68\%) of the participants were able to identify stress in at least two out of three of the words. The majority of them were able to identify the stressed syllable in the word 'handbag' (81\%) compared to just over half of them for the other two words (see Figure 4). Based on the overall results for questions 2 of the LSAT, it can be inferred that the participants found it easier to determine stress in disyllabic and trisyllabic words compared to words with prefixes and suffixes, and compound words.

\section{Production task}

Tables 5 to 7 present the acoustic measurements of the four test words from the recordings of 35 participants. The measurements include the three acoustic correlates of stress which are duration (in milliseconds), amplitude (in $\mathrm{dB}$ ) and the fundamental frequency or F0 (in Hertz). As shown in Table 5 and Figure 5, on average, the vowels in three out of four of the test words were produced longer on the second syllable: 'body', 'city' and 'disease'. This corresponds to the tendency to lengthen final vowels in words in the Malaysian variety of English (Gut \& Pillai, 2014). The results of the paired ttest found that two of the words displayed significant differences between the average vowel durations of the two syllables: 'city' $(t(34)=3.97 p=0.003)$ and 'disease' $(t(34)=3.46 p=0.001)$. Only the word 'office' was pronounced with a slightly longer vowel in the first syllable but the difference, as expected, was not significant.

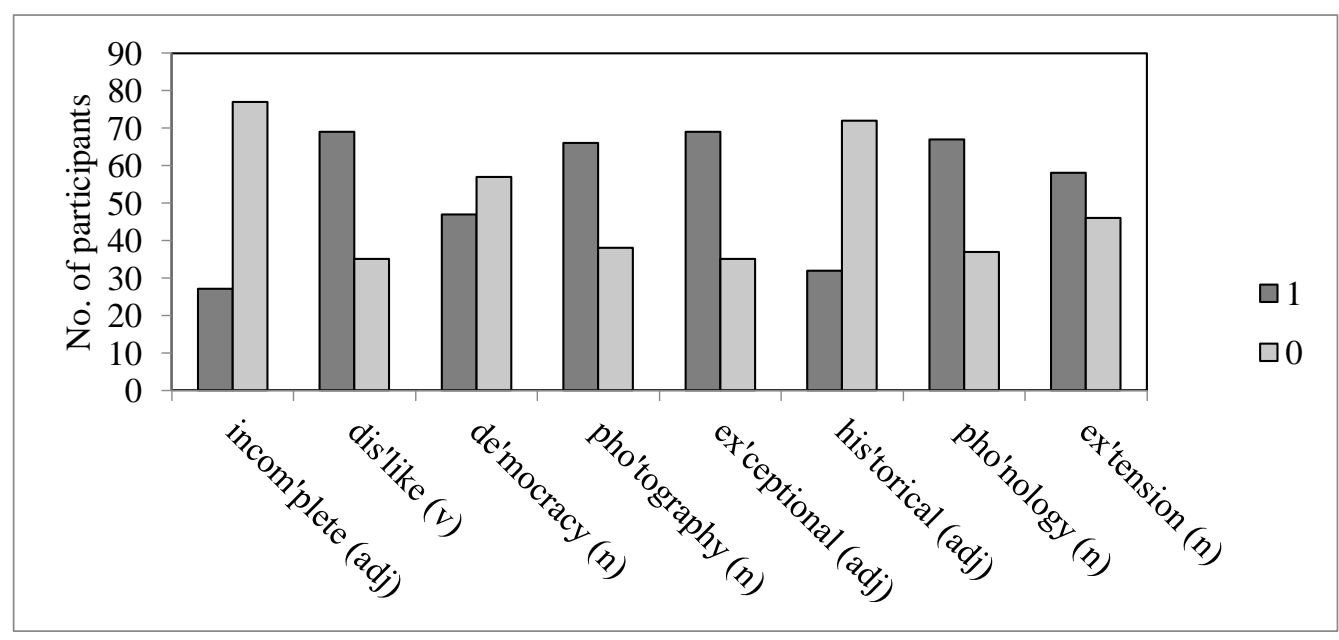

1: Identified stressed syllable

0: Did not identify stressed syllable

Figure 3. Identification of stressed syllables in words with prefixes and suffixes 


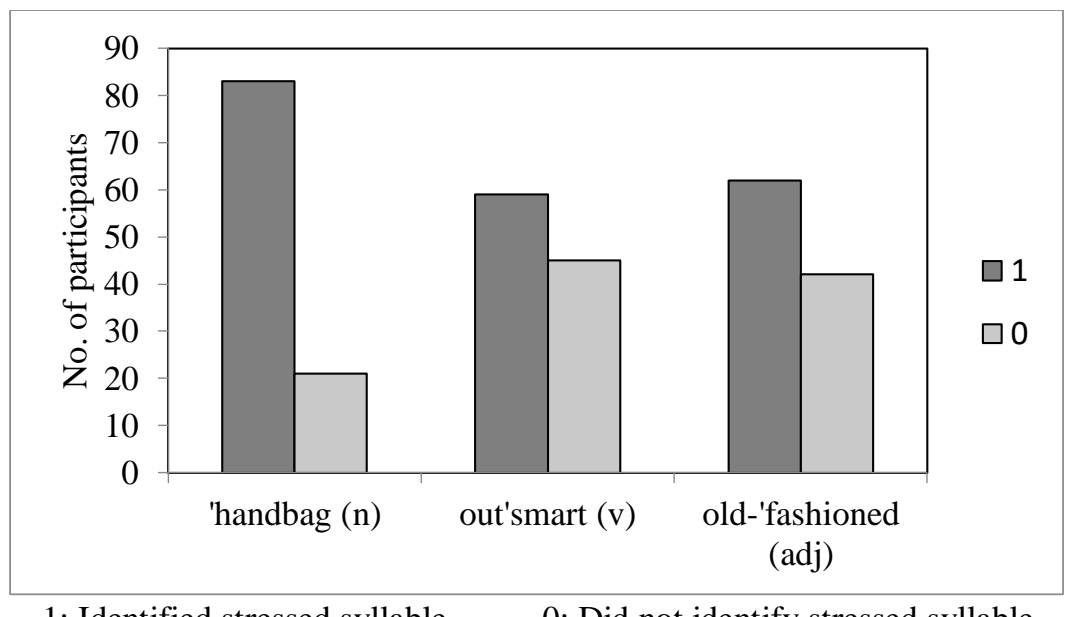

1: Identified stressed syllable $\quad 0$ : Did not identify stressed syllable

Figure 4. Identification of stressed syllables in compound words

However, the frequency of vowels which were longer in either the first or second syllable indicates that vowel lengthening was not always present. For the word 'body', the vowel in the second syllable was longer in 19 instances compared to 16 in the first syllable, while for the word 'city', it was longer in 22 of the 35 productions. For the word 'disease', 25 of the vowels in the second syllable were longer than in the first ones, and for the word 'office', 22 of the vowels in the first syllable were longer than the ones in the second syllable.

Table 5. Average vowel duration in disyllabic nouns

\begin{tabular}{|c|c|c|c|c|c|c|c|c|}
\hline \multirow{2}{*}{ Test words } & \multicolumn{2}{|c|}{$\underline{\text { body }}$} & \multicolumn{2}{|c|}{ office } & \multicolumn{2}{|c|}{$\underline{\text { city }}$} & \multicolumn{2}{|c|}{ disease } \\
\hline & S1 & S2 & S1 & S2 & S1 & S2 & S1 & S2 \\
\hline Average vowel duration (ms) & $124(18)$ & $128(33)$ & $91(22)$ & $87(21)$ & $59(14)$ & $73(25)$ & $110(26)$ & $137(32)$ \\
\hline Significance $(p)$ & \multicolumn{2}{|c|}{.482} & \multicolumn{2}{|c|}{.338} & \multicolumn{2}{|c|}{0.003} & \multicolumn{2}{|c|}{0.001} \\
\hline
\end{tabular}

S1: First syllable S2: Second syllable

Standard deviations are provided in parenthesis

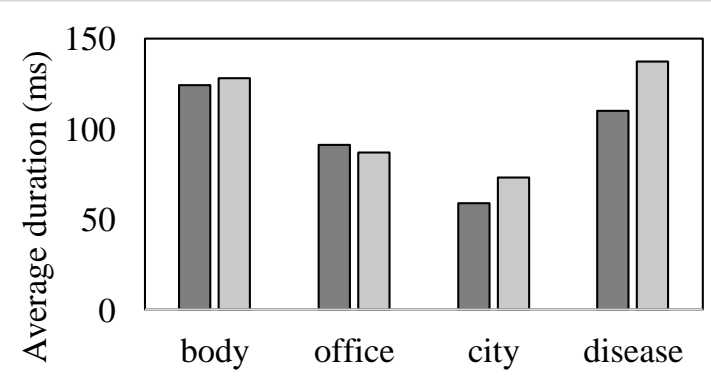

$\square$ First syllable $\square$ Second syllable

Figure 5. Average vowel duration in disyllabic nouns

Table 6 and Figure 6 display the average amplitude (dB) for the vowel in each syllable of the four disyllabic nouns produced by the speakers. As can be seen in Table 6, the first syllable in the words 'body' and 'office' were produced louder than the other syllable in these words. In contrast, the vowel in the second syllable was pronounced slightly louder than the first syllable in the word 'city'. For the word 'disease', the vowels in both syllables had similar amplitudes although the average duration of the second syllable was longer (see previous paragraph). However, paired samples t-tests found no significant difference in all the four test words in terms of their average vowel amplitude between the two syllables: 'office' $(t(34)=$ $1.29, p=.204)$, 'city' $(t(34)=0.75, p=.460)$ and 'disease' $(t(34)=0.13, p=.898)$. These results suggest that there was generally no difference in terms of how the two syllables were produced where amplitude was concerned. A significant difference was only found for the word 'body' $(t(34)=7.92 p=0.000)$, which had a louder first syllable but longer second syllable (see previous paragraph), although the difference for vowel length was not found to be significant.

The frequency of vowels with a higher intensity mirror the findings reported in Table 6. For the word 'body', the vowel in the first syllable had a higher intensity in 30 out of the 35 productions, while for the word 'office', it was higher in 19 of the instances. For the word 'city', there were 17 instances where the vowels in the first syllable were of higher intensity, and for the word 'disease', equal numbers of first and second syllables had vowels of higher intensity than the one in the other syllable.

The results on the average $\mathrm{F} 0(\mathrm{~Hz})$ of the vowels in each syllable in the four disyllabic nouns produced by the Malay speakers of English are presented in Table 7.

Due to general differences in the pitch range between adult male and females the average pitch for males and females were analysed separately. 
Table 6. Average vowel amplitude in disyllabic nouns

\begin{tabular}{|c|c|c|c|c|c|c|c|c|}
\hline \multirow{2}{*}{ Test words } & \multicolumn{2}{|c|}{ body } & \multicolumn{2}{|c|}{ office } & \multicolumn{2}{|c|}{ city } & \multicolumn{2}{|c|}{ disease } \\
\hline & S1 & S2 & S1 & S2 & S1 & S2 & S1 & $\mathbf{S 2}$ \\
\hline Average vowel amplitude (dB) & $57(3)$ & $54(3)$ & $54(4)$ & $53(3)$ & $51(3)$ & $52(4)$ & $54(4)$ & $54(3)$ \\
\hline Significance $(p)$ & \multicolumn{2}{|c|}{0.345} & \multicolumn{2}{|c|}{.3787} & \multicolumn{2}{|c|}{.6624} & \multicolumn{2}{|c|}{.9587} \\
\hline
\end{tabular}

S1: First syllable S2: Second syllable

Standard deviations are provided in parenthesis

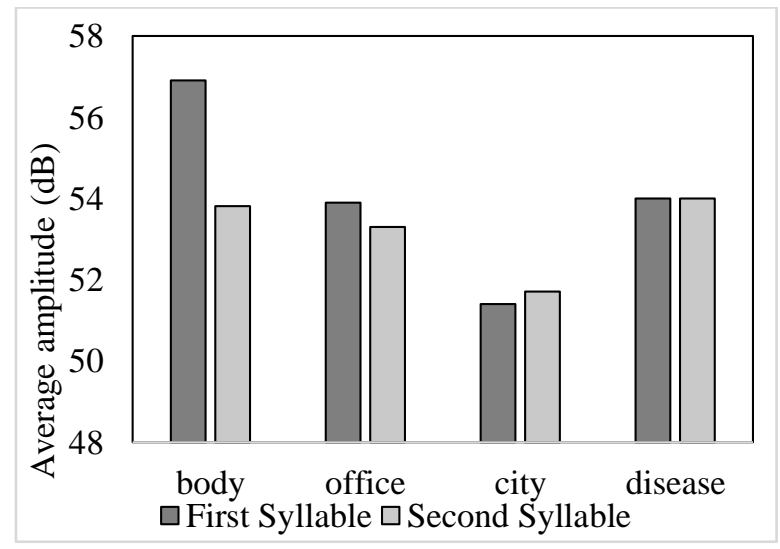

Figure 6. Average vowel amplitude in disyllabic nouns

For the female participants, the average pitch change was higher in the second syllable for all the words. Based on paired-samples t-tests significant differences were found between the average pitch change in the two syllables for 'body' $(t(29)=3.30, p=$ $.003)$, 'office' $(t(29)=1.91, p=.007)$ and disease' $(t(29)=5.87, p=.000)$. No significant difference was found for 'city' $(t(29)=1.41, p=.017)$. This would suggest more prominence being given to the second syllable, which in turn may be perceived as being stressed. In many of the cases there was a declining pitch pattern for both syllables as illustrated in Figure 7.

For the male speakers, the pattern was more inconsistent there was a higher average pitch change in the second syllable in the words 'office' and 'city'. The average pitch change was found to be higher in the first syllable of the word 'body'. The same declining pitch can also be observed for the male speakers.

Table 8 shows the average F0 of at syllable onset and offset in the words produced by the female and male participants. For the female speakers, a step-up from the offset of the first syllable to the onset of the second syllable is reflected in all four of the test words. This step up is visible can be seen in Figure 7. For the male speakers, a step-up can be seen in all the words except for 'city' (Table 8 and Figure 8). Similar step-up patterns were reported by (Tan, 2016). Like the findings for duration, this step up may be indicative of more prominence being given to the final syllable, hence, supporting the syllable-final lengthening phenomenon in the Malaysian variety of English. However, given the differing patterns found in the data, the findings are inconclusive.

Table 7. Average pitch change in disyllabic nouns

\begin{tabular}{|c|c|c|c|c|c|c|c|c|}
\hline \multirow{2}{*}{ Test words } & \multicolumn{2}{|c|}{ body } & \multicolumn{2}{|c|}{ office } & \multicolumn{2}{|c|}{ city } & \multicolumn{2}{|c|}{ disease } \\
\hline & S1 & $\mathbf{S 2}$ & S1 & S2 & S1 & $\mathbf{S 2}$ & S1 & S2 \\
\hline $\mathrm{F}$ & & & & & & & & \\
\hline Average vowel pitch change & 0 & 15 & 11 & -5 & -23 & -31 & -15 & 25 \\
\hline M & & & & & & & & \\
\hline Average vowel pitch change & -8 & -2 & 13 & -29 & -22 & -22 & -8 & 3 \\
\hline
\end{tabular}

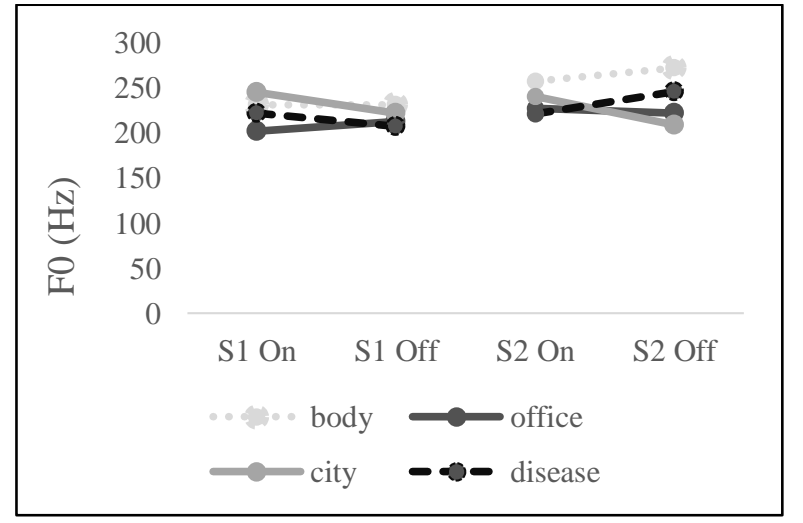

S1: First syllable On: Syllable onset Off: Syllable offset
Table 8 . Average pitch in syllable onset and offset

\begin{tabular}{lcccc}
\hline \multirow{2}{*}{ Words } & \multicolumn{2}{c}{ S1 } & \multicolumn{2}{c}{ S2 } \\
& On & Off & On & Off \\
\hline body F & 231 & 231 & 257 & 272 \\
body M & 137 & 129 & 140 & 138 \\
office F & 202 & 213 & 227 & 222 \\
office M & 108 & 121 & 150 & 121 \\
city F & 245 & 222 & 240 & 209 \\
city M & 171 & 149 & 142 & 120 \\
disease F & 222 & 207 & 221 & 246 \\
disease M & 128 & 120 & 128 & 131 \\
S1: First syllable & \multicolumn{3}{c}{ S2: Second syllable } \\
On: Syllable onset & Off: Syllable offset \\
F: Female & \multicolumn{3}{l}{ M: Male }
\end{tabular}

Figure 7. Average pitch patterns for female Malay speakers 


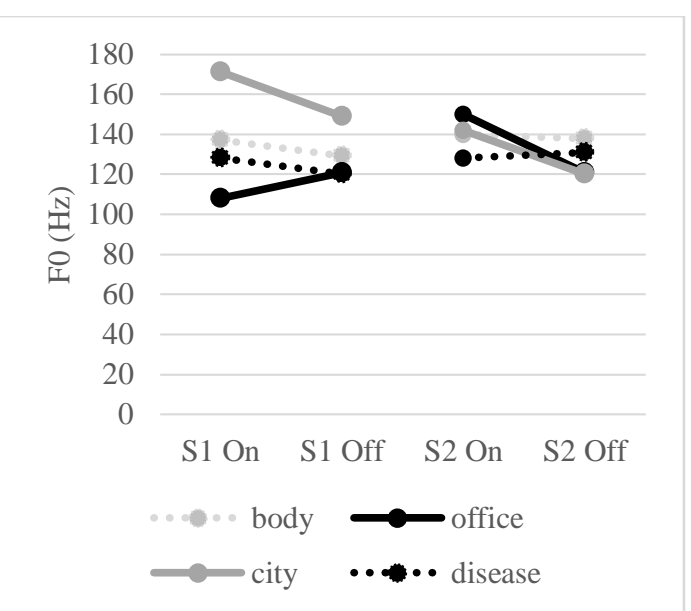

Figure 8. Average pitch patterns for male Malay speakers

\section{DISCUSSION}

Overall, based on the final scores of the test which were then matched to the levels of lexical stress awareness, the majority of the participants were placed at the intermediate level of awareness (see Table 2). The descriptors for this level suggest that the participants demonstrated only a satisfactory level of awareness as well as understanding of key concepts of English lexical stress. These concepts include identifying the characteristics of word stress and distinguishing between primary and secondary stress. The responses provided by the participants suggest that that many of them were not familiar with the characteristics of stress or were perhaps unable to articulate what these concepts were. This is despite having completed two modules of Linguistics and Phonetics and Phonology in their degree programme where the topic related to stress is covered. The topic focuses on the definition of related terms with brief illustrations of how stress is applied in words and in sentences in English.

Based on the answers provided in the LSAT, a higher pitch and a longer duration were commonly identified as characteristic of stress. This somewhat contrasts to what Tan (2006) found about Singaporean speakers who perceived loudness as the main indication of stress. Loudness was also among the characteristics selected by the Malaysian participants in Tan's study (2016, p. 78) where about $25 \%$ of them thought that stressed syllables should be longer, higher and louder, while others believed they should be louder and longer or be of a higher pitch. Similar to Tan (2016), the mixed responses from the participants in the present study suggest a lack of awareness about stress in general, and how they themselves produce stress.

In fact, in their own production, it appears that duration rather than pitch or amplitude, is the most prominent feature where in three of the four words, the vowel in the second syllable was produced with a longer duration. In other words, the results from LSAT and the production task were inconsistent in terms of the correlates of stress described by the participants in the
LSAT and their actual production. As previously mentioned, this may be an effect of syllable final lengthening common among Malaysian speakers of English (Mat Nayan \& Setter, 2016; Rajadurai, 2006). Thus, even though vowel or syllable length is a characteristic of a stressed syllable, these lengthened syllables in the data may not correspond to the assigned stress in, for example, BrE. Similar discrepancies were reported by Tan (2016). The three correlates of stress did not appear to be used together consistently. For example, a syllable with a longer vowel did not necessarily also have a higher pitch or rising pitch pattern, and neither was it necessarily louder. The patterns of use for all three correlates were generally inconsistent especially for amplitude and pitch. This suggests that these are not commonly employed by speakers to distinguish between syllables. Where pitch is concerned, this is consistent with findings about how Malay speakers mark new and given information (Gut \& Pillai, 2014).

Despite of the difficulties faced in describing the characteristics of stress, the participants generally displayed a satisfactory level of sensitivity towards the general rules of lexical stress in words as reflected in their identification of stressed syllables in the LSAT. Most of them identified the stress syllable in disyllabic and trisyllabic words better than in words with prefix and suffixes, and compound words. This may be because of the categories of these words. The disyllabic and trisyllabic words in the LSAT are root words, and perhaps, this made it easier for the participants to apply underlying rules of stress to the test words based on their prior knowledge of how these words are pronounced. In contrast, rules for stress in words with prefixes and suffixes, and compound words are more challenging.

As mentioned previously in this section, there is a mismatch between the participants' level of awareness of lexical stress and their actual production in terms of what they thought were the main charateriscs of stress. Similarly, their identification of stressed syllables in disyllabic and trisyllabic words, and how they produced such words did not always correspond. If we look at duration, where there were the most significant differences between syllables (compared to pitch and amplitude), the longer durations of the second syllables in the words 'body' and 'city' may be perceived as stress. However, the stress on the second syllable of these words does not correspond to stress in RP where the first syllable is stressed and the final one tends to contain a short tense vowel (/i/). The lack of significance between the vowel durations in the first and second syllable in two of the words suggest that the two syllables were not produced differently. In short, even if the participants knew which the stressed syllable was in citation form, they did not necessarily transfer this knowledge into their production. This is understandable given that the knowledge of stress in citation form may be based on RP since this is the pedagogical model in schools and ITEs. However, their spoken form of 
English is not RP and it displays different features including how stress is produced (if at all). Based on the frequency of syllables with longer vowel durations, for example, it would appear that stress placement was random. In other words, based on the assumption that duration is a correlate of stress, neither the first nor the second syllable was consistently stressed. This inconsistency is perhaps not surprising given that the Malaysian variety of Malay, which is the first language of the speakers, does not have lexical stress (Mohd. Don, Knowles \& Yong, 2008).

The inconsistency between the participants level of awareness and their actual production, and their rather random placement of stress indicate that there is a need to create more awareness about lexical stress in English among the participants. The finding that stress placement is inconsistent, and the tendency to lengthen final syllables could affect intelligibility. NonMalaysian speakers may find it difficult to make out what is being said due to these factors. The importance of stress for speech to be intelligible is still being debated (Derwing \& Munro, 2015; Jenkins, 2009; Shah, Othman, \& Senom, 2017). However, teachers of English should know how stress is assigned and be aware of the correlates of stress in the variety of English used as a pedagogic model and their own variety of English. Such knowledge can help teachers grapple with having to teach pronunciation features that may be different from their own (Pillai, 2017). It can help them to be more confident when dealing with lexical stress, and to make better classroom decisions. This could include, for example, focusing on vowel or syllable length as a main correlate of stress, and also working on communicative strategies to mitigate such misunderstandings.

The performance of the participants in the LSAT suggests that the sections in the curriculum that is allocated to stress and perhaps other aspects of the sound system of English need to be re-examined. This should be done not only to inculcate a better understanding of the sounds of the pedagogic variety of English but also to examine features of pronunciation in the Malaysian variety of English. In relation to knowledge of the system and awareness of the local variety, trainees should also explore ways to teach different aspects of pronunciation. In this way the current situation of teachers largely ignoring pronunciation in the English language classroom can be contained (Jayapalan \& Pillai, 2011; Nair, Krishnasamy, \& de Mello, 2006; Rajadurai, 2006; Shah, Othman, \& Senom, 2017). As discussed in the introduction section of this paper, awareness of different varieties of English is important for teachers (Tupas, 2010).

\section{CONCLUSION}

The first question we addressed was the level of awareness of English lexical stress among a group of teacher trainees. Based on the LSAT, most of the trainees were placed at the intermediate level and above.
However, almost half of them were not able to describe key concepts related to lexical stress and also identify stressed syllables. They appeared to have some underlying knowledge of lexical stress placement in English words but struggled when the words had prefixes (e.g., 'incomplete') and suffixes (e.g., historical') or were compound words (e.g., 'outsmart')

Secondly, we examined the acoustic characterises of lexical stress in the production of the four words. The three features (duration, pitch and amplitude) were generally not used together consistently to distinguish between syllables. The duration of vowels appeared to be the main feature used to distinguish between two syllables. In particular, the intensity of vowels was not found to be major distinguishing feature. The frequency of using these features suggests that even duration was used randomly to distinguish between syllables which in turn is indicative of an unsystematic realisation of lexical stress among the trainees.

The third aspect we examined was the link between the level of awareness and the production of lexical stress among the trainees. A missmatch between the two was found in terms of the characteristics of stress they described and the main feature of stress found in their production. Whilst a higher pitch was frequently provided as a characterisc of stress, they most frequency used duration to distinguish between two syllables. Another mismatch was that although the trainees were generally able to identify stressed syllables in citation form, they did not necessarily replicate this knowledge in their production where the placement of stress was relatively random.

The findings contribute to our understanding of the realisation of stress in the Malaysian variety of English. It also provides information on the level of awareness of lexical stress among English language teacher trainees. The findings suggest that more needs to be done during the teacher training programme to inculcate a better understanding of stress and other features of the sound system of English. At the same time, the finding can be used to create awareness of their own variety of English. Knowledge of both varieties will enable teachers to make more informed pedagogical decision.

\section{ACKNOWLEDGEMENT}

This research was supported by the Ministry of Education, Malaysia through a Federal Training Scholarship (Hadiah Latihan Persekutuan) for the Doctor of Philosophy Programme.

\section{REFERENCES}

Baskaran, L. (2004). Malaysian English: Phonology. In B. Kortmann, E. W.Schneider, K. Burridge \& C. Upton (Eds.), A handbook of varieties of English volume 1: Phonology (pp. 1034-1046). Berlin: Mouton de Gruyter.

Boersma, P., \& Weenink, D. (2017). Praat: Doing phonetics by computer. [Computer program]. 
Version 6.0.28. Retrieved from

http://www.praat.org.

Derwing, T. M., \& Munro, M. J. (2015). Pronunciation fundamentals: Evidence-based perspectives for $\mathrm{L} 2$ teaching and research. Amsterdam/Philadelphia: John Benjamins.

Field, J. (2005). Intelligibility and the listener: The role of lexical stress. TESOL Quarterly, 39(3), 399423. https://doi.org/10.2307/3588487

Fry, D. B. (1958). Experiments in the perception of stress. Language and Speech, 1(2), 126-152. https://doi.org/10.1177/002383095800100207

Gut, U., \& Pillai, S. (2014). Prosodic marking of information structure by Malaysian speakers of English. Studies in Second Language Acquisition, 36(2), 283-302.

https://doi.org/10.1017/S0272263113000739

Hashim, A., \& Tan, R. (2012). Malaysian English. In E. L. Low \& A. Hashim (Eds.), English in South East Asia: Features, policy and language in use (pp. 55-74). Amsterdam: John Benjamins.

Jayapalan, K., \& Pillai, S. (2011). The state of teaching and learning English pronunciation in Malaysia: A preliminary study. Malaysian Journal of ELT Research, 7(2), 63-81. Retrieved from https://journals.melta.org.my/index.php/majer/artic le/view/155/70.

Jenkins, J. (2009). (Un)pleasant? (In)correct? (Un)intelligible? ELF speakers' perceptions of their accents. In A. Mauranen \& E. Ranta (Eds.), English as a Lingua Franca. Studies and findings (pp. 10-35). Cambridge: Cambridge Scholars Publishing.

Jeong, H., Thorén, B., \& Othman, J. (2017). Mutual intelligibility of Malay and Swedish accented English: An experimental study. Indonesian Journal of Applied Linguistics, 7(1), 43-53. http://dx.doi.org/10.17509/ijal.v7i1.6857.

Kementerian Pendidikan Malaysia. (2015). Kurikulum standard sekolah rendah: Dokumen standard kurikulum dan pentaksiran (draf) tahun enam. Putrajaya: Kementerian Pendidikan Malaysia.

Kementerian Pendidikan Malaysia. (2016). Kurikulum standard sekolah menengah Bahasa Inggeris: Dokumen standard kurikulum dan pentaksiran. Putrajaya: Kementerian Pendidikan Malaysia.

Leech, G., Rayson, P., \& Wilson, A. (2001). Word frequencies in written and spoken English. Retrieved from http://ucrel.lancs.ac.uk/bncfreq/.

Lehiste I. (1970). Suprasegmentals. Cambridge, MA: MIT Press.

Low, E.-L. (2015). The rhythmic patterning of English(es). In M. Reed \& J. M. Levis (Eds.), The handbook of English pronunciation (pp. 125-137). Chichester: Wiley Blackwell.

Mat Nayan, N. F., \& Setter, J. (2016). Malay English intonation: The cooperative rise. English World-
Wide, 37(3), 293-322.

https://doi.org/10.1075/eww.37.3.03mat.

Mohd. Don, Z., Knowles, G., \& Yong, J. (2008). How words can be misleading: A study of syllable timing and 'stress' in Malay. The Linguistics Journal, 3(2). Retrieved from https://www.linguisticsjournal.com/2014/01/08/how-words-can-bemisleading-a-study-of-syllable-timing-and-stressin-malay/

Nair, R., Krishnasamy, R., \& de Mello, G. (2006). Rethinking the teaching of pronunciation in the ESL classroom. The English Teacher, XXXV, 2740. Retrieved from https://journals.melta.org.my/index.php/tet/article/ view/312/208

Pillai, S. (2017). Local features of English pronunciation: To embrace or ignore in the ELT classroom? Journal of English Language, Literature, and Teaching, 1(1), 1-8. Retreived from http://journal2.um.ac.id/index.php/jellit/article/vie w/962/560

Pillai, S., \& Ong, L. T. (2018) English(es) in Malaysia. Asian Englishes, 20(2), 147-157. https://doi.org/10.1080/13488678.2018.1459073.

Platt, J. T. (1980). Varieties and functions of English in Singapore and Malaysia. English World-Wide, 1(1). 97-121. https://doi.org/10.1075/eww.1.1.08pla.

Rajadurai, J. (2006). Pronunciation issues in non-native contexts: A Malaysian case study. Malaysian Journal of ELT Research, 2(1), 42-59. Retrieved from

https://journals.melta.org.my/index.php/majer/artic le/view/170/84.

Roach, P. (2009). English phonetics and phonology: A practical course ( $4^{\text {th }}$ edition). Cambridge: Cambridge University Press.

Shah, S. S. A., Othman, J., \& Senom, F. (2017). The pronunciation component in ESL Lessons: Teachers' beliefs and practices. Indonesian Journal of Applied Linguistics, 6(2), 193-203. http://dx.doi.org/10.17509/ijal.v6i2.4844

Tan, R. S. K. (2016). How do we stress? Lexical stress in Malaysian and British English. In T. Yamaguchi \& D. Deterding (Eds.), English in Malaysia: Current use and status (pp. 65-88). Boston: Brill.

Tan, Y. Y. (2006). Is the stressed syllable stressed? The perception of prominence in Singapore English. In A. Hashim \& N. Hassan (Eds.), Varieties of English in Southeast Asia and beyond (pp.133152). Kuala Lumpur: University of Malaya Press.

Tupas, T. R. F. (2010). Which norms in everyday practice - and why? In A. Kirkpatrick,(Ed.), The Routledge handbook of World Englishes (pp. 567579). New York: Routledge. 